\title{
Dietary fibre intake and clinical indices in the French Supplementation en Vitamines et Minéraux AntioXydants (SU.VI.MAX) adult cohort
}

\author{
Denis Lairon ${ }^{1 *}$, Sandrine Bertrais ${ }^{2}$, Stephanie Vincent ${ }^{1}$, Nathalie Arnault ${ }^{2}$, \\ Pilar Galan ${ }^{2}$, Marie-Christine Boutron ${ }^{2}$ and Serge Hercberg ${ }^{2}$ \\ ${ }^{1}$ Unité 476 Human Nutrition and Lipids at INSERM (National Institute of Health and Medical Research), \\ Faculty of Médecine, 27 Bd J. Moulin, 13385 Marseille cedex 5, France \\ ${ }^{2}$ Mixed Unit 555 INSERM-U 1125 INRA-CNAM, Nutritional Epidemiology and Surveys, Paris, France
}

\begin{abstract}
The aim of our study was to investigate the relationship between dietary fibre intake and some clinical indices, blood biochemical variables and the incidence of cardiovascular disease and cancers in France, taking advantage of an ongoing cohort, the Supplementation en Vitamines et Minéraux AntioXydants (SU.VI.MAX) intervention study. This preliminary report provides data on dietary fibre intake in this French adult population group of 4080 subjects (2168 men and 1912 women) aged 45-65 years at inclusion. The data obtained for fibre intake indicate that most men and women have low to moderate intakes of total dietary fibre (mean 21.0 and $17.1 \mathrm{~g} / \mathrm{d}$ respectively), with only $21 \%$ of the men and $7 \%$ of the women having total dietary fibre intakes at the recommended level (i.e. $>25 \mathrm{~g} / \mathrm{d}$ ) and soluble fibre accounting for $19 \%$ of the total dietary fibre intake for both genders. The main food sources of dietary fibre are cereals (30-35\% total), vegetables (20-24\% total) and fruit (19-22\% total). No marked regional differences were observed within France. The highest dietary fibre intakes have been found to be associated with a lower BMI, blood systolic pressure, plasma triacylglycerols and plasma glucose in men and lower BMI in women. Overall, these data support the concept of a beneficial effect of a high dietary fibre intake on cardiovascular disease risk.
\end{abstract}

Dietary fibre intake: Cardiovascular risk: Health status: SU.VI.MAX study

With some exceptions, traditional dietary patterns are essentially based on vegetable foodstuffs that were minimally processed, or not processed, until the last century. Based on cereals, pulses, fruits and vegetables, these diets provided an important supply of dietary fibre. These dietary patterns are still maintained by most populations living in developing countries and vegetarians in Western countries. Conversely, the recent and drastic changes that have occurred in industrialized countries have led to dietary patterns mostly based on animal foodstuffs and refined cereals, with a reduced supply of dietary fibre. In fact, dietary fibre has long been considered a non-useful food component and regarded as waste to feed animals (i.e. brans and germs). This attitude started to change in the 1970s after the pioneering observation by Burkitt \& Trowell (1975) of the different incidences of a number of diseases in the native and white populations in Africa. These authors suggested that a lack of dietary fibre could be involved in the aetiology of some Western diseases, such as constipation, diverticulosis, cardiovascular disease or cancers. Since this observation was reported, many studies have been performed to test such hypotheses and elucidate some of the mechanisms involved. The information available has been updated in recent proceedings of international scientific conferences (i.e. those held in Dublin, Republic of Ireland, 2000 and in Porvoo, 2001; 6th Vahouny Fibre Symposium held in Washington, DC, 2000; the present symposium). In the last decade several key epidemiological studies have been published that link dietary fibre intake and cardiovascular risk. One of the pioneer studies (Kromhout et al. 1982) showed a four-fold lower cardiovascular death rate in men ingesting high amounts of fibre $(\geq 37 \mathrm{~g} / \mathrm{d})$ compared with those ingesting the lowest amounts $(<20 \mathrm{~g} / \mathrm{d})$. More recently, a 6-year prospective study conducted on a large cohort of adult men aged 40-75 years in the USA (Rimm et al. 1996) showed an inverse relationship between fibre 
intake and cardiovascular death, with an odds ratio of 0.6 found for a fibre intake of about $30 \mathrm{~g} / \mathrm{d}$ compared with the lowest quintile (10-17 g/d). Similar data have been obtained in other surveys conducted on young men in the USA (Ludwig et al. 1999) and on European adults (Pietinen et al. 1996). It was found in the latter study that a daily intake of $3 \mathrm{~g}$ soluble fibre $(\mathrm{SF})$ was associated with a $27 \%$ reduction in cardiovascular mortality. A more recent 10 -year survey performed on a large cohort of women aged 37-64 years in the USA (Wolk et al. 1999) showed that women in the highest quintile of fibre intake $(22.9 \mathrm{~g} / \mathrm{d})$ have a $34 \%$ lower risk of CHD than those in the lowest quintile $(11.5 \mathrm{~g} / \mathrm{d})$. This observation has been confirmed by another survey of adult women in the USA (Liu et al. 2002). Finally, a recent meta-analysis performed on some selected recent surveys confirms the protective effect of dietary fibre against cardiovascular disease (Anderson et al. 2000). In most surveys cereal fibres have been shown to be strongly associated with the reduced risk observed. This finding is supported by other recent data showing a protective effect of whole grains (Jacobs et al. 1998; Liu et al. 1999). Nevertheless, experimental and clinical studies have repeatedly shown evidence that SF from various sources only has a hypocholesterolaemic effect (Lairon, 1996; Brown et al. 1999; Fernandez, 2001). As almost all previous surveys have been performed outside Europe, it was planned to carry out a prospective survey in France. Advantage was taken of the ongoing Supplementation en Vitamines et Minéraux AntioXydants (SU.VI.MAX) intervention study (Hercberg et al. 1998) to evaluate an expected relationship linking dietary fibre intake with some clinical indices, blood biochemical variables and the incidence of cardiovascular disease and cancers. In the present report the emphasis will be on the assessment of dietary fibre intake in the French adult population. Indeed, very limited data have been available on dietary fibre intake in France until now, as confirmed during a European evaluation on dietary fibre intakes performed in 1993 (Lairon \& Barry, 1993). Further reports will deal with details of clinical and biochemical data or mortality incidence.

\section{The design of the Supplementation en Vitamines et Minéraux AntioXydants study}

The SU.VI.MAX study is a randomized double-blind placebo-controlled primary-prevention trial designed to test the efficacy of daily supplementation with antioxidant vitamins (vitamin C $120 \mathrm{mg}$, vitamin E $30 \mathrm{mg}$, $\beta$-carotene $6 \mathrm{mg}$ ) and minerals (Se $100 \mu \mathrm{g}, \mathrm{Zn} 20 \mathrm{mg}$ ) at nutritional doses in reducing several major health problems in industrialized countries, and especially the main causes of premature death (cancers and cardiovascular diseases; Hercberg et al. 1998).

The study was started in 1994 in France. The 12735 eligible subjects included in the study (women aged 35-60 years and men aged 45-60 years) were allocated randomly to the supplement or placebo groups and will be monitored for 8 years (until Spring 2003). Participants visit the clinic once yearly, and in alternate years undergo either biological sampling or clinical examination. Data on baseline characteristics of the participants suggest that the present sample closely represents the national population in terms of geographic density, socio-economic status and the distribution of various major risk factors for the diseases under study. The choice of the study population should allow the results of this trial to be applicable to adult populations of both genders in France and other industrialized countries.

At regular intervals volunteers provide information on health events and compliance (every month), and on dietary intake (ideally every 2 months) by filling out computerized questionnaires using the Minitel Telematic Network developed for the purpose (contact: hercberg@vcnam. cnam.fr). To obtain reliable dietary intake data, the subjects have been given a validated questionnaire together with instruction manuals for coding foods, including photographs for selecting seven different portion sizes.

\section{Dietary fibre and the Supplementation en Vitamines et Minéraux AntioXydants study}

In order to conduct this evaluation it was necessary to have a food and nutrient database with accurate dietary fibre contents. Until now, The REGAL food database (CiQUAL, Paris, France) has mainly been used in France. This database provides total fibre contents essentially based on values obtained using the Southgate (1969) method of analysis. The SU.VI.MAX food database also used these values.

In order to obtain more reliable data and to be able to evaluate total dietary fibre (TDF) and SF separately, a new database was compiled with TDF and SF contents obtained from food analyses conducted using the widelyacknowledged method of the Association of Official Analytical Chemists for fibre analysis (Prosky et al. 1988) with some modifications. Values were obtained mostly from the literature, and in some other cases from unpublished laboratory data (C Hoebler, C Cherbut and $\mathrm{P}$ Dyssler). When data derived using the Association of Official Analytical Chemists method were not available (e.g. for some food items of minor importance), earlier values were used. For mixed dishes (e.g. pizza, couscous), fibre contents were calculated using TDF and SF contents of the individual foodstuffs and the usual recipes.

In order to study specific relationships between dietary fibre intake and other variables and end points, a subsample of 4080 subjects aged 45-60 years was selected from the whole group of the SU.VI.MAX cohort. Among the 2168 men the distribution (\%) by age-groups was as follows: $45-49$ years $32 \cdot 7,50-54$ years $31 \cdot 5$, 55-60 years $28 \cdot 3$, 60-65 years 7.6. Among the 1912 women the distribution (\%) by age groups was as follows: 45-49 years $43 \cdot 5,50-54$ years $28 \cdot 8,55-60$ years $22 \cdot 4,60-65$ years $5 \cdot 3$.

Participants were recruited from all regions of France (eight large geographical areas) and from all socio-economic categories. The relative distribution (\%) within occupational categories for men and women respectively was: farmers $1.3,1.1 ;$ skilled workers and self-employed 4.8, 2.9; executives 38.9, 17.0; professionals (e.g. teachers, nurses) 20.9, 29.9; administrative workers 9.8, 16.6; unskilled workers $2 \cdot 9,1 \cdot 2$; retired $13 \cdot 9,7 \cdot 2$; unemployed $4 \cdot 7,4.6$.

Mean daily TDF and SF intakes were calculated from twelve different $24 \mathrm{~h}$ dietary records obtained from each subject during the 4 years after inclusion in the study. 


\section{Dietary fibre intake in the Supplementation en Vitamines et Minéraux AntioXydants cohort}

\section{Total and soluble fibre intake}

The participants consumed a typical Western diet. Men and women respectively showed the following mean dietary intake pattern (\% energy without alcohol): daily energy intake 9522 (SD 42), 7010 (SD 41) KJ; alcohol 7.3, 3.8\% energy; protein $18 \cdot 3,18 \cdot 3$; fat $39 \cdot 5,39 \cdot 6$; carbohydrate $42 \cdot 3$, $42 \cdot 1$.

A summary of key data obtained for fibre intakes is given in Fig. 1. The mean daily TDF intake was 21.0 (SD 6.9) $\mathrm{g}$ for men and 17.1 (SD 5.3) $\mathrm{g}$ for women. The median value for TDF intake was 20.2 and $16.5 \mathrm{~g} / \mathrm{d}$ for men and women respectively.

In fact, the range of TDF intake was very large, i.e. $3.0-63.2 \mathrm{~g} / \mathrm{d}$ for men and $3 \cdot 7-47.9 \mathrm{~g} / \mathrm{d}$ for women. As shown in Table 1 , about $18.5 \%$ of the men ingested $<15 \mathrm{~g}$ TDF/d, while most men ingested $15-25 \mathrm{~g} / \mathrm{d}$. It is notable that only about $25 \%$ of the men ingested $>25 \mathrm{~g}$ TDF/d. For women (Table 1), $5.8 \%$ ingested $<10 \mathrm{~g}$ TDF/d, while most women had TDF intakes of between 10 and $20 \mathrm{~g} / \mathrm{d}$. A minority of women (about $7 \%$ ) had TDF intakes $>25 \mathrm{~g} / \mathrm{d}$.

The mean daily intake of SF was 3.9 (SD 1.3) $\mathrm{g}$ for men and $3.4(\mathrm{SD} 1.1) \mathrm{g}$ for women. Median values were 3.8 and $3.3 \mathrm{~g} / \mathrm{d}$ for men and women respectively. Thus, SF accounted for $18.6 \% \mathrm{TDF}$ for men and $19.9 \% \mathrm{TDF}$ for women.

Taken together, these values are comparable with those reported from other European countries (Lairon \& Barry, 1993; Pietinen et al. 1996) and the USA (Rimm et al. 1996; Wolk et al. 1999).

These data indicate that the observed mean TDF intake is clearly below the recommended daily intake, which has recently been updated in France to $25-30 \mathrm{~g}$ TDF/d (ANC, 2001). Moreover, it is striking that only a minority of adult men and women have a TDF intake that meets the

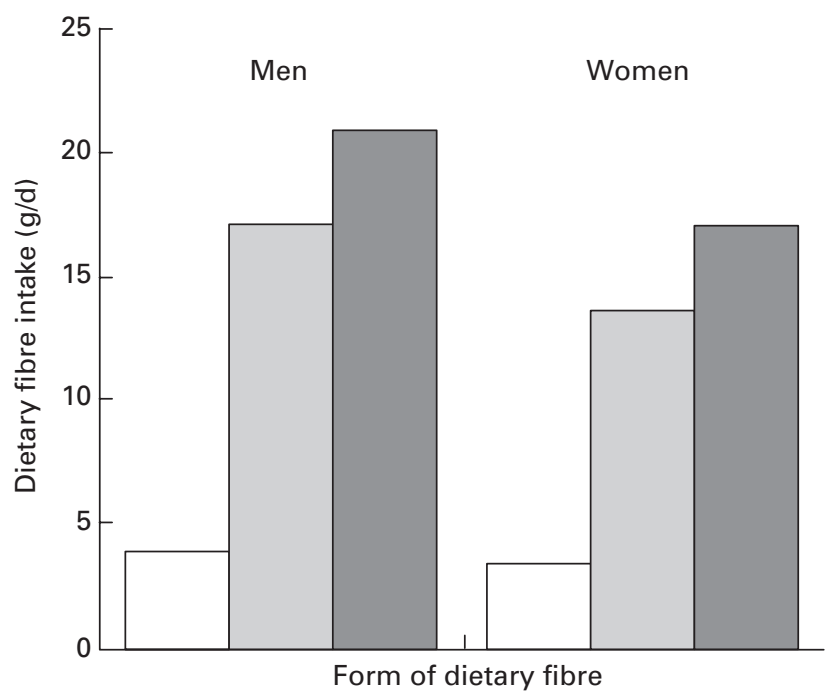

Fig. 1. Dietary fibre intakes of men and women participating in the Supplementation en Vitamines et Minéraux AntioXydants Study. $(\square)$, Soluble fibre; (四), insoluble fibre; $(\square)$, total dietary fibre. For details of subjects and procedures, see p. 12. recommended daily intake. Thus, it is noteworthy that an appreciable percentage of these adult men (18.5) and women (37.9) had very low TDF intakes, i.e. $<15 \mathrm{~g} / \mathrm{d}$.

\section{Factors influencing fibre intake}

Dietary pattern. For men and women a significant relationship $(P=0.0001)$ between total dietary energy intake and TDF intake was observed when subjects were distributed among five quintiles for TDF intake. A similar relationship was found for SF intake $(P=0.0001)$.

Age at inclusion. For men a significant trend $(P=0.0009)$ towards higher TDF intake with age was observed, with lower values for groups aged $45-50$ and 50-55 years (20.8 and $20.3 \mathrm{~g} / \mathrm{d}$ respectively) and higher values for groups aged 55-60 and 60-65 years ( 21.6 and $22.1 \mathrm{~g} / \mathrm{d}$ respectively). This trend was not observed for women in the different agegroups with comparable TDF intakes (range 16.8-17.2 g/d). A significant trend towards higher SF intake with age was observed for men (range 3.9-4.2 g/d; $P=0.002$ ) and women (range $3 \cdot 3-3.5 \mathrm{~g} / \mathrm{d} ; P=0 \cdot 05$ ).

Level of education. Participants were grouped according to level of education: primary school; secondary school; university. For both men and women TDF intakes (19.9, 21.3 and $21.4 \mathrm{~g} / \mathrm{d}$ respectively for men; 16.4, 17.1 and $17.5 \mathrm{~g} / \mathrm{d}$ respectively for women) and SF intakes (3.7, 3.9 and $4.0 \mathrm{~g} / \mathrm{d}$ respectively for men; $3 \cdot 3,3.4$ and $3.5 \mathrm{~g} / \mathrm{d}$ respectively for women) were positively associated with the level of education $(P=0.04$ to $P=0.0001)$.

Occupation. For men there was no noticeable difference in TDF and SF intakes for the different occupational categories. However, for women significant differences $(P=0.0004)$ were found, with the highest TDF (and SF) intakes for farmers and retired women $(19.6$ and $18.3 \mathrm{~g} / \mathrm{d}$ respectively) and the lowest intakes for those who do not work and in administrative workers (16.3 and $16.5 \mathrm{~g} / \mathrm{d}$ respectively).

Geographic location. The participants all lived within one of the eight large regional zones in France (Paris and surrounding areas, centre-east, north-west, north-east, west, south-west, Rhône valley-Alps-Central massif, Mediterranean coast).

There were no important differences in TDF intakes (and $\mathrm{SF}$, data not shown) between the eight French regions (range $20 \cdot 3-21.9 \mathrm{~g} / \mathrm{d}$ for men and $16 \cdot 5-17.9 \mathrm{~g} / \mathrm{d}$ for women). This finding is possibly related to the generally low fibre intake and the fact that several food sources provide the greater part of dietary fibre, as reported later.

Table 1. Distribution (\% total no. of subjects) of total dietary fibre (TDF) intake among men and women participating in the Supplementation en Vitamines et Minéraux AntioXydants study

\begin{tabular}{lcc}
\hline TDF intake $(\mathrm{g} / \mathrm{d})$ & Men $(n 2168)$ & Women $(n$ 1912) \\
\hline $0-10$ & $3 \cdot 0$ & $5 \cdot 8$ \\
$10-15$ & $15 \cdot 5$ & $32 \cdot 1$ \\
$15-20$ & $29 \cdot 8$ & $36 \cdot 9$ \\
$20-25$ & $26 \cdot 7$ & $18 \cdot 0$ \\
$\geq 25$ & 24.9 & $7 \cdot 2$ \\
\hline
\end{tabular}




\section{Food sources of dietary fibre}

The relative importance of food sources for dietary fibre supply is illustrated in Fig. 2.

For men TDF is mainly provided by cereals (about $35 \%$ of the TDF ingested) and to a lesser extent by vegetables and fruit (each about $20 \%$ of the TDF ingested). Pulses (about $4 \%$ of the TDF ingested) and drinks (about $2.6 \%$ of the TDF ingested) provided marginal amounts of fibre. SF was provided to a comparable extent by cereals, vegetables and fruit (each about $25 \%$ of the TDF ingested).

For women cereals provided about $30 \%$ of the TDF ingested, while vegetables and fruit each accounted for about $25 \%$ of the TDF ingested. Pulses (about $3.5 \%$ of the TDF ingested) and drinks (about $2 \%$ of the TDF ingested) provide marginal amounts of fibre. SF was mainly provided by vegetables (about $28 \%$ of the TDF ingested), fruit (about $24 \%$ of the TDF ingested) and cereals (about $21 \%$ of the TDF ingested).

With few exceptions, it was not possible to show evidence of noticeable differences in the relative importance of the different food items as a fibre source in the eight French regions. This finding is probably due to the present dominant way of life, which dramatically reduces local cultural traits and leads to uniformity of dietary habits.

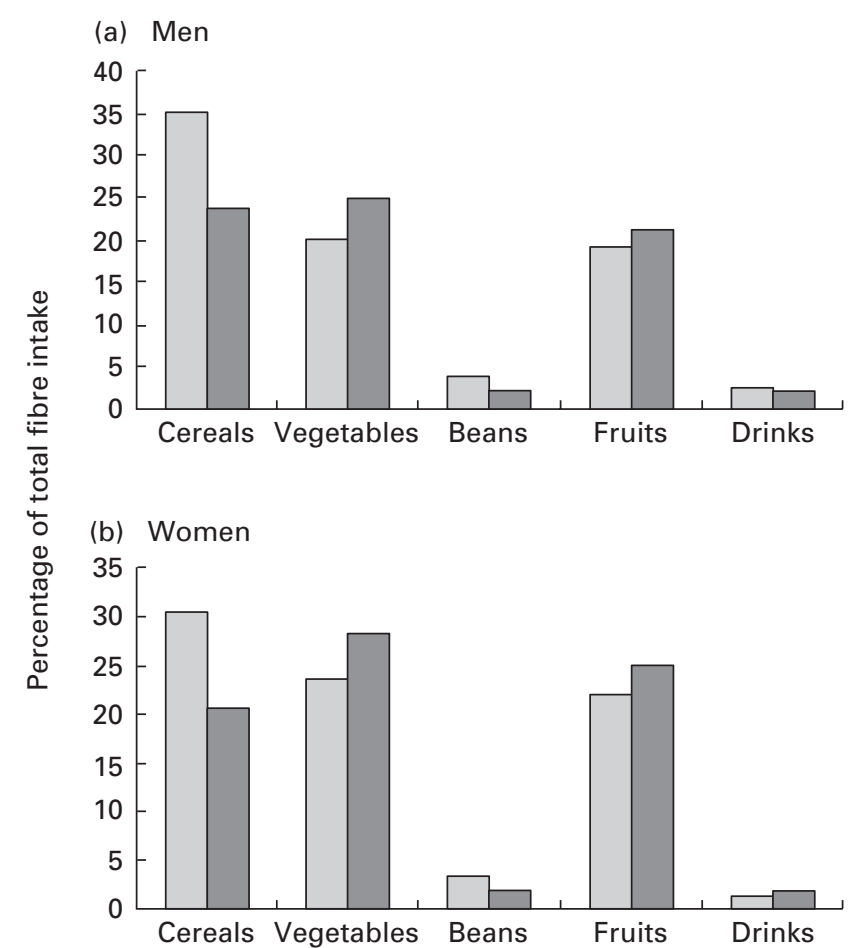

Fig. 2. Contribution of different food sources to the dietary fibre intakes of men and women participating in the Supplementation en Vitamines et Minéraux AntioXydants Study. (四), Soluble fibre; $(\boldsymbol{\square})$, total dietary fibre. For details of subjects and procedures, see p. 12 .

\section{Dietary fibre intake and cardiovascular risk factors}

A number of clinical and biochemical indices were determined when participants joined the study. Preliminary data for some variables are presented in Table 2 and are shown as the relative mean difference $(\%)$ between the highest and the lowest quintiles of TDF intake.

For men a number of significant differences were found between the subjects in the highest and the lowest quintiles of TDF intake $(>26.3 \mathrm{~g} / \mathrm{d} v .<15.2 \mathrm{~g} / \mathrm{d})$; these variables included lower BMI, systolic blood pressure, fasting plasma cholesterol, triacylglycerols and glucose. Cereal fibre was the source most consistently associated with the studied variables.

For women the only significant difference between those subjects with the highest $v$. the lowest quintile of TDF intake $(>21.1 \mathrm{~g} / \mathrm{d} v .<12.7 \mathrm{~g} / \mathrm{d})$ was observed for BMI, with only vegetable fibre displaying an effect.

The data obtained, especially those for men, show good agreement with published data (Jenkins et al. 1993; Pietinen et al. 1996; Rimm et al. 1996; Ludwig et al. 1999; Wolk et al. 1999; Liu et al. 2002).

\section{Conclusion}

The present study is the first one performed in France that allows a sound and detailed evaluation of dietary fibre intake for men and women at the population level.

The data obtained for fibre intake show that men and women have low to moderate intakes of TDF, with only $21 \%$ men and $7 \%$ women having TDF intakes at the recommended level; SF accounts for $19 \%$ of the TDF intake for both men and women. The main food sources of TDF

Table 2. Comparison of clinical and biochemical indices for the highest and lowest quintiles of dietary fibre intake for men and women participating in the Supplementation en Vitamines et Minéraux AntioXydants study

\begin{tabular}{|c|c|c|c|}
\hline Variable & Gender & $\begin{array}{c}\text { Change (\%) } \\
\text { highest } v . \text { lowest } \\
\text { TDF intake quintile* }\end{array}$ & $\begin{array}{c}\text { Fibre source } \\
\text { effect } †\end{array}$ \\
\hline \multirow[t]{2}{*}{ BMI (w/h²) } & Men & -4.9 & TDF, CF, FF \\
\hline & Women & $-1 \cdot 3$ & VF \\
\hline \multirow{2}{*}{$\begin{array}{l}\text { Systolic pressure } \\
\qquad(\mathrm{mmHg})\end{array}$} & Men & $-3 \cdot 8$ & TDF, CF \\
\hline & Women & $-2 \cdot 2$ & \\
\hline \multirow{2}{*}{$\begin{array}{l}\text { Plasma cholesterol } \\
\qquad(\mathrm{mmol} / \mathrm{l})\end{array}$} & Men & $-3 \cdot 2$ & \\
\hline & Women & +0.1 & \\
\hline \multirow{2}{*}{$\begin{array}{c}\text { Plasma triacylglyc- } \\
\text { erols }(\mathrm{mmol} / \mathrm{l})\end{array}$} & Men & $-16 \cdot 2$ & TDF \\
\hline & Women & $-10 \cdot 0$ & \\
\hline \multirow{2}{*}{$\begin{array}{l}\text { Plasma glucose } \\
\qquad(\mathrm{mmol} / \mathrm{l})\end{array}$} & Men & $-5 \cdot 2$ & CF \\
\hline & Women & $-2 \cdot 3$ & \\
\hline
\end{tabular}

TDF, total dietary fibre; CF, cereal fibre; VF, vegetable fibre; FF, fruit fibre.

*TDF intakes for the lowest and highest quintiles: men, $<15.2$ and $>26.3 \mathrm{~g} / \mathrm{d}$ respectively; women, $<12.7$ and $>21.1 \mathrm{~g} / \mathrm{d}$ respectively. Relative changes (\%) were calculated as follows :

lowest quintile value - highest quintile value $\times 100$. lowest quintile value

tComparison between 1st and 5th quintiles for TDF, CF, VF or FF, adjusted for energy intake. The effect of the fibre source indicated was significant (Bonferoni test; $P<0.05$ ). 
are cereals (30-35\%), vegetables (20-24\%) and fruits (19-22\%). Overall these values are comparable with those obtained in other industrialized countries. No marked regional differences were observed in France.

The highest dietary fibre intakes have been found to be associated with lower BMI, blood systolic pressure, plasma cholesterol, triacylglycerols and glucose in men; cereal and vegetable fibre being the most effective. For women lower plasma triacylglycerols and trends towards lower BMI, blood systolic pressure and plasma glucose have been found; cereal fibre being the most effective. Overall, these data support the concept of a beneficial effect of a high dietary fibre intake on cardiovascular disease risk and are in line with those published from studies performed in the USA and in other European countries.

Detailed clinical data and the incidence of cardiovascular events and cancer cases in relation to fibre intake in this cohort will be reported in future publications.

\section{References}

ANC (2001) Apports Nutritionnels Conseillés pour la Population Française (Recommended Nutrient Intakes for the French Population), 3rd ed. [A Martin, editor]. Paris: Editions Tec et doc.

Anderson JW, Hanna TJ, Peng X \& Kryscio RJ (2000) Whole grain foods and heart disease risk. Journal of the American College of Nutrition 19, 291S-299S.

Brown L, Rosner B, Willett WW \& Sacks FM (1999) Cholesterollowering effects of dietary fiber: a meta-analysis. American Journal of Clinical Nutrition 69, 30-42.

Burkitt DP \& Trowell HS (1975) Refined Carbohydrate Foods and Disease: Some Implications of Dietary Fibre. London: Academic Press.

Fernandez ML (2001) Soluble fiber and nondigestible carbohydrate effects on plasma lipids and cardiovascular risk. Current Opinion in Lipidology 12, 35-40.

Hercberg S, Préziosi P, Briançon S, Galan P, Triol I, Malvy D, Roussel A-M \& Favier A (1998) A primary prevention trial using nutritional doses of antioxidant vitamins and minerals in cardiovascular diseases and cancers in the general population: the SU.VI.MAX study-design, methods, and participant characteristics. Controlled Clinical Trials 19, 339-351.

Jacobs DR, Meyer KA, Kushi LH \& Folsom AR (1998) Wholegrain intake may reduce the risk of ischemic heart disease death in postmenopausal women: the Iowa Women's Health Study. American Journal of Clinical Nutrition 68, 248-257.

Jenkins DJA, Spadafora PJ, Jenkins AL \& Rainey-Macdonald CG (1993) Fiber in treatment of hyperlipidemia. In Handbook of Dietary Fiber in Human Nutrition, pp. 419-433 [GA Spiller, editor]. Boca Raton, FL: CRC Press.

Kromhout D, Bosschieter EB \& De Lezenne Coulander C (1982) Dietary fibre and 10-year mortality from coronary heart disease, cancer and all causes. Lancet ii, 518-522.

Lairon D (1996) Dietary fibers: effects on lipid metabolism and mechanisms of action. European Journal of Clinical Nutrition 50, 125-133.

Lairon D \& Barry JL (1993) Dietary fibre intake in France. In Dietary Fiber Intake in Europe, pp. 49-52 [JH Cummings, editor]. Brussels: COST 92 Action Printing Office.

Liu S, Buring JE, Sesso HD, Rimm EB, Willett WC \& Manson JE. (2002) A prospective study of dietary intake and risk of cardiovascular disease among women. Journal of the American College of Cardiology 39, 49-56.

Liu S, Stampfer MJ, Hu FB, Giovannucci E, Rimm E, Manson JE, Hennekens CH \& Willett WC (1999) Whole-grain consumption and risk of coronary heart disease: results from the Nurses' Health Study. American Journal of Clinical Nutrition 70, 412-419.

Ludwig DS, Pereira MA, Kroenke CH, Hilner JE, Van Horn L, Slattery ML \& Jacobs DR (1999) Dietary fiber, weight gain, and cardiovascular disease risk factors in young adults. Journal of the American Medical Association 282, 1539-1546.

Pietinen P, Rimm EB, Korhonen P, Hartman AM, Willett WC, Albanes D \& Virtamo J (1996) Intake of dietary fiber and risk of coronary heart disease in a cohort of Finnish men. Circulation 94, 2720-2727.

Prosky L, Asp NG, Schweitzer TF, DeVries JW \& Furda I (1988) Determination of insoluble, soluble and total dietary fiber in foods and food products: interlaboratory study. Journal of the Association of Official Analytical Chemists 71, 1017-1023.

Rimm EB, Ascherio A, Giovannucci E, Spiegelman D, Stampfer MJ \& Willett WC (1996) Vegetable, fruit, and cereal fiber intake and risk of coronary heart disease among men. Journal of the American Medical Association 275, 447-451.

Southgate DAT (1969) Determination of carbohydrates in foods. II Unavailable carbohydrate. Journal of the Science of Food and Agriculture 20, 331-335.

Wolk A, Manson JE, Stampfer MJ, Colditz GA, Hu FB, Speizer FE, Hennekens CH \& Willett WC (1999) Long-term intake of dietary fiber and decreased risk of coronary heart disease among women. Journal of the American Medical Association 281, 1998-2004. 